\title{
ULTIMATE CAPACITY OF PAD EYES USED FOR LIFTING OPERATIONS: EXPERIMENTAL AND NUMERICAL SIMULATIONS
}

\author{
HIKMAT SAAID SALEH, SAMDAR KAKAY \& SUDATH C. SIRIWARDANE \\ Department of Structural and Mechanical Engineering and Materials Science, Faculty of Science and Technology, \\ University of Stavanger, Norway.
}

\begin{abstract}
Load capacities of pad eyes used in offshore lifting operations are generally determined based on the guidelines given in lifting standards. In 2012, NORSOK issued a new standard, R-002 'Lifting equipment', to ensure that adequate safety requirements are complied with in connection with lifting operations on the Norwegian continental shelf. To ensure the accuracy of the followed design procedure, this paper presents a comparison of theoretical load capacities of 3.25-ton pad eyes with experimentally and numerically predicted load capacities. Several laboratory tests have been performed to conduct experimental analyses of the load capacities of pad eyes. These tests have included different pinhole sizes in the pad eyes, different strain directions of pad eye pinholes and different loads to which the pad eyes were subjected. Finite element (FE) simulation was performed for two different cases: with base plate and without base plates. The obtained numerical results show that the addition of the plate to the pad eyes increased the capacity of the pad eyes. It also shows that load capacity of the pad eyes gradually decreased with the increase in pinhole size. This shows the importance of following the standard's requirements. The comparison of results shows that some of the load capacities provided by the FE analysis closer to the experimental and the theoretical results, while a few others were quite far from them. These differences have been comprehensively discussed in the latter part of the paper. Keywords: FE analysis, load testing, offshore lifting, pad eyes
\end{abstract}

\section{INTRODUCTION}

Offshore activities on the Norwegian continental shelf include the lifting from sea to platform, using a platform crane, of smaller modification structures. Objects vary in shape, size and weight, many weighing below 50 tons, and it would be of great advantage if calculations regarding such lifting operations could be standardized.

In 2012, NORSOK issued a new standard, R-002 'Lifting equipment' [1], to ensure that adequate safety requirements are complied with in connection with lifting operations on the Norwegian continental shelf. Among the lifting equipment, pad eyes and shackles play a major role in ensuring the safety of lifting operations [1-4].

The most commonly used theoretical approaches for estimating the load capacity of pad eyes are mainly based on stress limit states. This practice does not capture the local deformation-induced buckling or twisting and large-plastic deformation at the interface of the pad eye and shackle. The finite element (FE) method employed numerical tools, which may help to solve this problem to some extent, but the lack of precious ductile failure criteria, which are employed in current commercial software [5, 6], may hinder in better prediction to load capacity and deformed behavior by numerical approach. To overcome these problems to some extent, tests are conducted to evaluate experimental load capacities for pad eyes and to study their behavior in plastic state of stress. However, the problem with experimental approaches is that they can be exhausting, time-consuming and somewhat expensive. Therefore, it is necessary to make available a simpler, equally precise, less time-consuming and more cost-effective approach for estimating load capacities of pad eyes. 
To ensure the accuracy of the followed design procedure, this paper presents a comparison of the theoretical load capacities of 3.25-ton pad eyes with experimental and numerical results. To conduct the experimental analyses of the design load capacity of pad eyes, several tests must be conducted, and a part of the results has been presented previously [7]. These tests include different pinhole sizes in the pad eyes, different strain directions of pad eye pinholes, and different loads to which the pad eyes were subjected. FE simulation was performed for two different cases: with base plate and without base plates. Initially, the paper reviews various factors that it is important to consider in a lifting operation and provides an important theoretical basis. Then, details related to the execution, analysis and results of the experimental testing are discussed briefly, while citing the authors' previous paper. The numerical approach associated with load capacity determination is comprehensively discussed in this paper. Finally, the load capacities obtained by the above three approaches are compared and their differences are discussed in the final part of the paper.

\section{PAD EYES AND SHACKLES}

This section describes the types of pad eyes (also called lugs) and the technical requirements for lifting operations. A demonstration of the lifting terminology is shown in Fig. 1. Three main types of design geometries for pad eyes are described in NORSOK R-002 lifting standard [1]. Type 1 is made of plate, with a uniform thickness, as shown in Fig, 2. Type 2 is made of cheek plates attached to the main plate by a fillet weld, as shown in Fig. 2, while type 3 consists of partly connected boss by full penetration welds as shown in Fig. 2.

Shackles are made up of a U-shaped body and a pin, often secured with a bolt. They are used together with different lifting devices, and the size of the shackle is relative to the hole diameter of the pad eye, as shown in Fig. 3. Pad eyes should also be designed to match the standard shackle dimension so that the shackle can house both the pad eye and the preferred sling or hook.

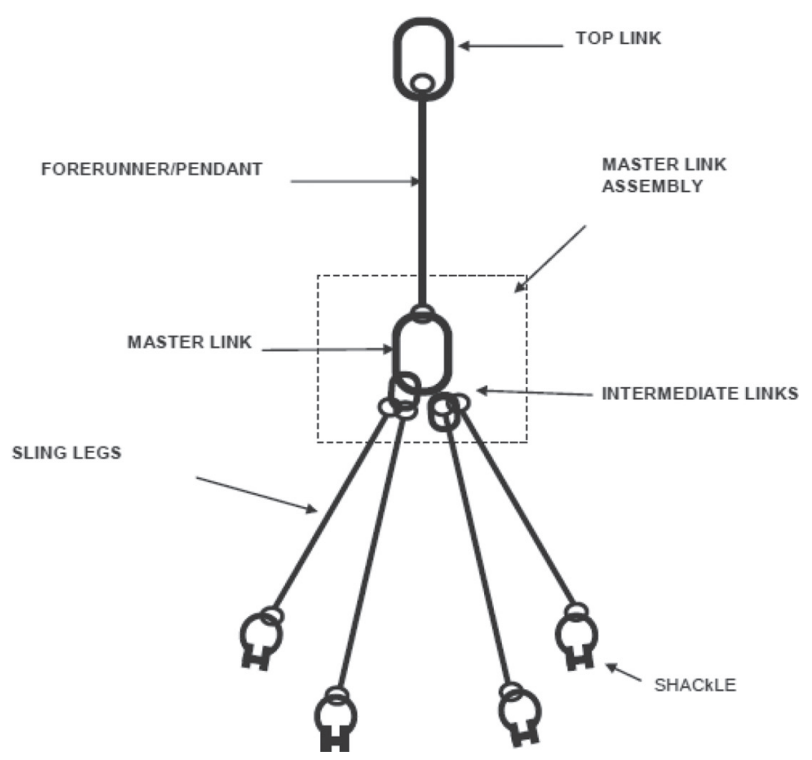

Figure 1: A demonstration of the lifting set terminology [7]. 



TYPE 1 1 for shackles with WLL $\leq 8.5$ Tonnes Load angle between $-90^{\circ} \leq \mathrm{D} \leq 90^{\circ}$

TYPE $2(W L L<55 T)$ Typical for shackles with WLL $\leq 55$ Tonnes Load angle between $-90^{\circ} \leq \mathrm{D} \leq 90^{\circ}$

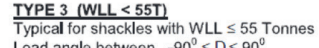
Load angle between $-90^{\circ} \leq \mathrm{D} \leq 90^{\circ}$

Figure 2: Different types of pad eyes.
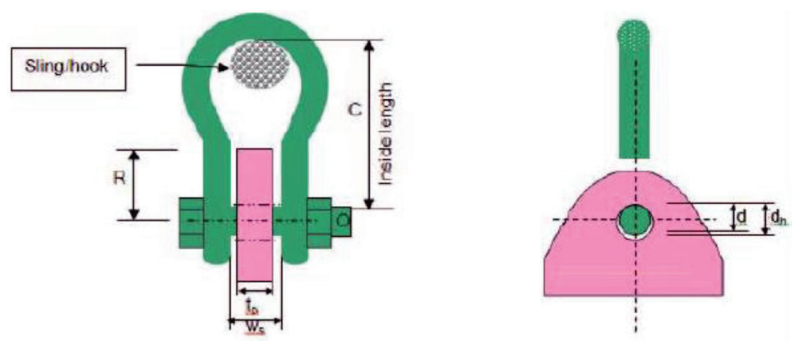

Figure 3: Pad eye and shackle interface.

\section{DESIGN LOAD CAPACITY: THEORETICAL APPROACH}

This section describes the design criteria that are used to predict the load capacities of pad eyes and shackles. This criteria-based approach is recognized as the most common and the one which is generally used for pad eyes and shackles.

The design tearing off load of pad eyes can be derived as,

$$
P_{t}=2 \tau_{R d} A_{s h}
$$

where $\tau_{R d}=f_{y} / \gamma_{m, 1} \sqrt{3}$ is the design shear strength, and $A_{s h}=\left(R-d_{h} / 2\right) t_{p}$ is the tearing out area. $f_{y}$ is the tensile yield strength of the plate material, and $\gamma_{m, 1}$ is the partial safety factor for the material specified by N-004 [8]. $R$ represents the outer radius, while $d_{h}$ is the hole diameter of the pad eye plate and $t_{p}$ is the thickness of the plate.

The design bearing load of the pad eyes can be obtained as,

$$
P_{b}=f_{b, R d} t_{e f f} d
$$

where $f_{b, R d}=1.5 f_{y} / \gamma_{m, 1}$ is the design shear strength and $t_{\text {eff }}=t_{p}$ is the effective thickness of the plate. $f_{y}$ is the tensile yield strength of the plate material and $t_{p}$ represents the thickness of the plate. $\gamma_{m, 1}$ is the partial safety factor for the material specified by N-004 [8], while $d$ is the diameter of the shackle bolt, as shown in Fig. 3. 


\section{LOAD CAPACITY: EXPERIMENTAL APPROACH}

This section describes the details of the specimens and the experimental test setup. The pad eyes, which have a safe working load (SWL) of 3.25 tons, are only tested in this study. The 10 different pad eyes were produced by changing the hole diameter. The geometrical details and more detailed information of the test program have been clearly stated in the published dissertation [7].

The pad eyes were welded to the plates using full penetration welds and 8-mm joints. The welds were then tested using magnetic particle inspection and ultrasound, the most commonly used NDT methods, to verify that the test specimens were fabricated with the desired fixity without significant defects. In addition to the pad eye test specimens, shackles with corresponding dimensions were also an important part of the tests. The shackles were used as connection points between the tension cylinder, the dynamometer and the pad eye specimens. Quasi-static load test were conducted by changing different directions, as shown in Table 1. The fracture loads and displacement at failure are recorded in Table 1. The deformed or fractured pad eye specimens are shown in Fig. 4, while the deformed shapes of some of the shackle components are as displayed in Fig. 5.

\section{LOAD CAPACITY: NUMERICAL APPROACH}

This section describes the details of the FE simulation and the load capacity estimation of same pad eyes, which have a SWL of 3.25 tons. The analysis was performed for two different cases: with base plate and without base plates. The general-purpose FE package, Abaqus/ CAE, is used for this analysis. S355 steel has been used for both pad eyes and base plates. The three FE models of case 1 (i.e. pad eye without base plate) are shown in Fig. 6. The other three FE models of case 2 (i.e. with pad eye with base plate) are shown in Fig. 7.

The elastic-plastic analysis of the pad eye using Abaqus/Explicit was then performed for all the test scenarios previously mentioned in Section 4. The nonlinear mix/combined hardening behavior of S355 steel was considered for elastic-plastic analysis. The obtained stress contours of the FE models are closely observed to recognize the critical zones and then for further mesh refinements. A mesh convergence test was also performed. The bottom surface of the FE models of case 1 was fixed. The fixed boundary was used at the

Table 1: Comparison of the load capacities of pad eyes.

\begin{tabular}{|c|c|c|c|c|c|c|c|}
\hline \multirow[b]{3}{*}{ Test } & \multirow{3}{*}{$\begin{array}{l}\text { Theoretical } \\
\\
\text { Load capacity } \\
\text { (Tons) }\end{array}$} & \multicolumn{2}{|l|}{ Experimental } & \multicolumn{4}{|c|}{ FEM simulation } \\
\hline & & \multirow[b]{2}{*}{$\begin{array}{l}\text { Load capacity } \\
\text { (Tons) }\end{array}$} & \multirow[b]{2}{*}{$\begin{array}{l}\text { Displacement } \\
(\mathrm{mm})\end{array}$} & \multicolumn{2}{|c|}{$\begin{array}{l}\text { Pad eye without } \\
\text { plate }\end{array}$} & \multicolumn{2}{|c|}{$\begin{array}{l}\text { Pad eye with } \\
\text { plate }\end{array}$} \\
\hline & & & & $\begin{array}{l}\text { Load } \\
\text { (Tons) }\end{array}$ & $\begin{array}{l}\text { Dis } \\
(\mathrm{mm})\end{array}$ & $\begin{array}{l}\text { Load } \\
\text { (Tons) }\end{array}$ & $\begin{array}{l}\text { Dis } \\
(\mathrm{mm})\end{array}$ \\
\hline 1 & 26.2 & $>21$ & 0.5 & 25.575 & 0.06 & 26.247 & 0.25 \\
\hline 3 & 20.7 & $>21$ & 3.5 & 22.179 & 0.18 & 24.464 & 0.75 \\
\hline 4 & 15.3 & 14.5 & large dis & 21.406 & 0.80 & 23.547 & 0.85 \\
\hline 5 & 26.2 & $>14$ & large dis & 22.493 & 0.0085 & - & - \\
\hline 6 & 20.7 & $>15$ & large dis & 21.904 & 0.150 & - & - \\
\hline 7 & 15.3 & $>14.5$ & large dis & 20.379 & 0.600 & - & - \\
\hline
\end{tabular}




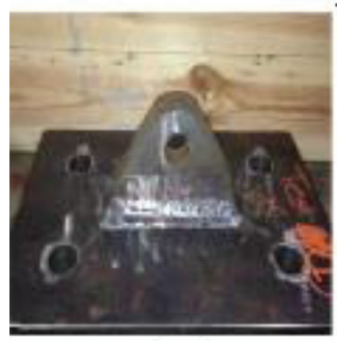

Test 1

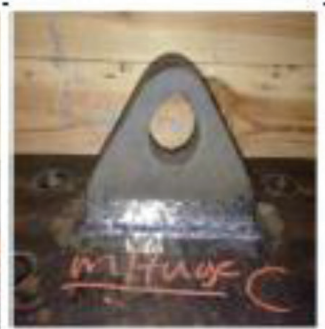

Test 3

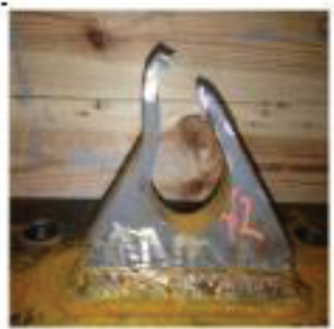

Test 4

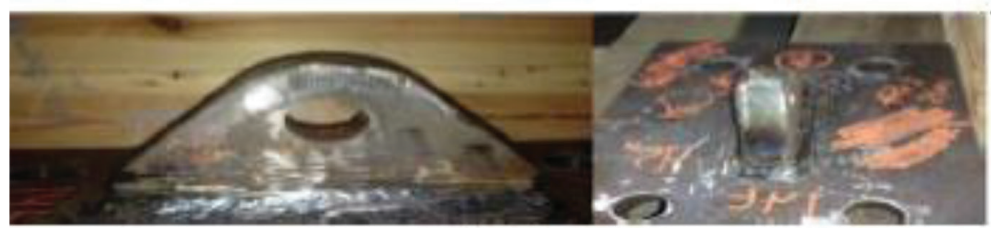

Test 5

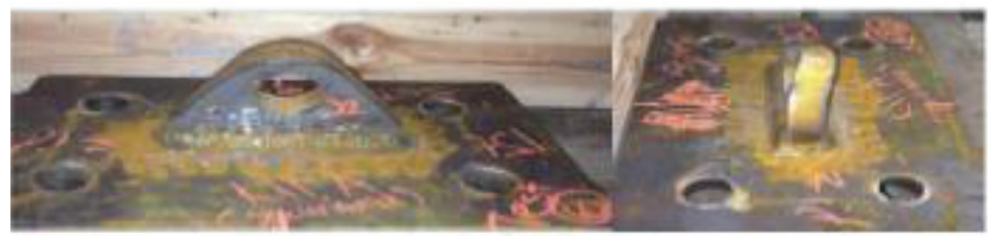

Test 6

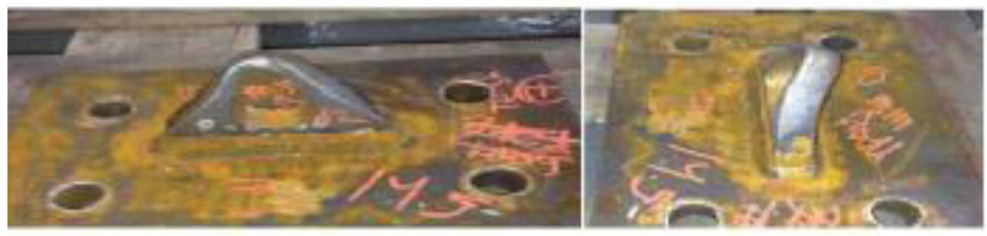

Test 7

Figure 4: Fractured or/and deformed test specimen of pad eyes [7].
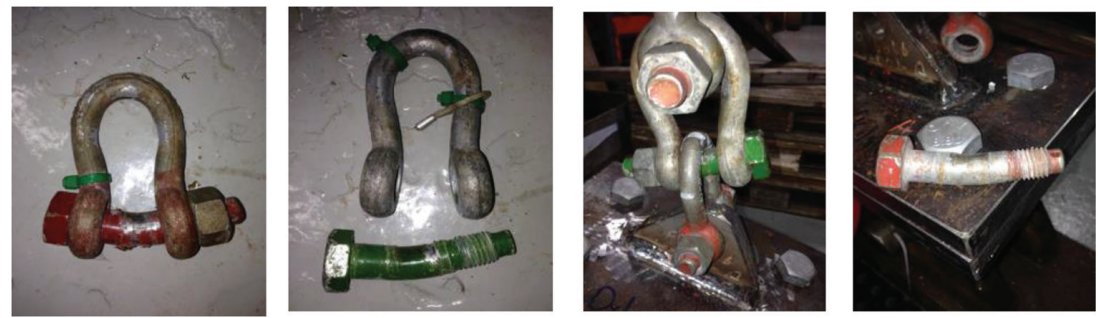

Figure 5: Permanent deformation of shackle components after the test [7].

circumference of the boltholes of the base plate. Both geometrical and material nonlinearity were considered in the incremental analysis. The FE simulation results, including locations vulnerable to ductile fracture, are shown in Figs 8 and 9 for cases 1 and 2, respectively. The load capacities were determined by considering the ductile fracture. The ductile 


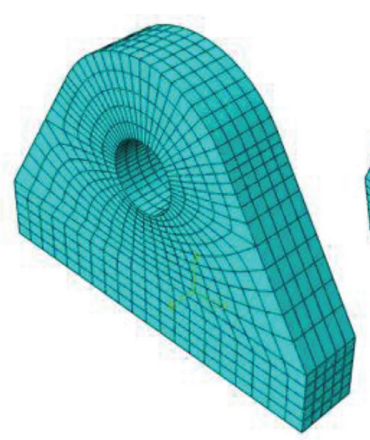

(a)

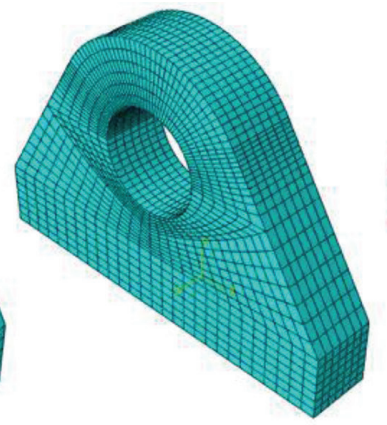

(b)

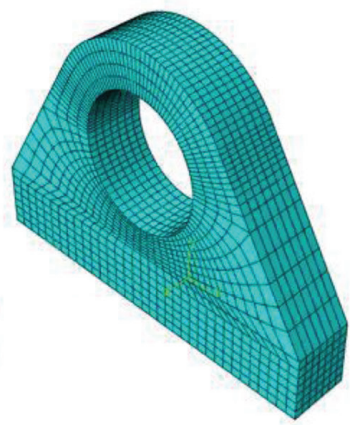

(c)

Figure 6: FE mesh of case 1 (i.e. pad eyes without base plate): (a) pinhole diameter $22 \mathrm{~mm}$, (b) pinhole diameter $32 \mathrm{~mm}$, (c) pinhole diameter $42 \mathrm{~mm}$.

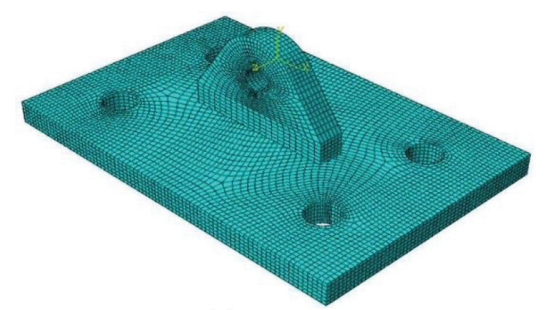

(a)

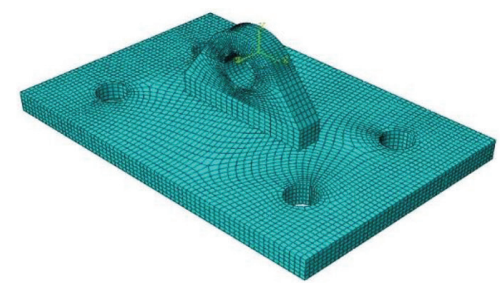

(b)

Figure 7: FE mesh of case 2 (i.e. pad eyes with base plate): (a) pinhole diameter $22 \mathrm{~mm}$, (b) pinhole diameter $32 \mathrm{~mm}$, (c) pinhole diameter $42 \mathrm{~mm}$.

fracture was determined when von Mises effective stress or strain exceeds material ultimate strength or strain, respectively. The obtained load capacities are shown in Table 1.

\section{COMPARISON AND DISCUSSION}

In this section, comparisons are made for all three different types of approaches for designing the load capacity of pad eyes. The experimental, theoretical and, finally, FE-simulation-based load capacities for the load capacity of 3.25-ton pad eyes are shown in Table 1. Each of the six tests in the table below are now discussed individually.

Test 1: In the case where the pad eye is without a plate, the load capacities given by FE analysis are larger than both the theoretical and the experimental load capacities, while the displacements are much smaller than the experimental deformation. In the case of the pad eye with the addition of the plate, the test specimens can carry the same amount of load as the 

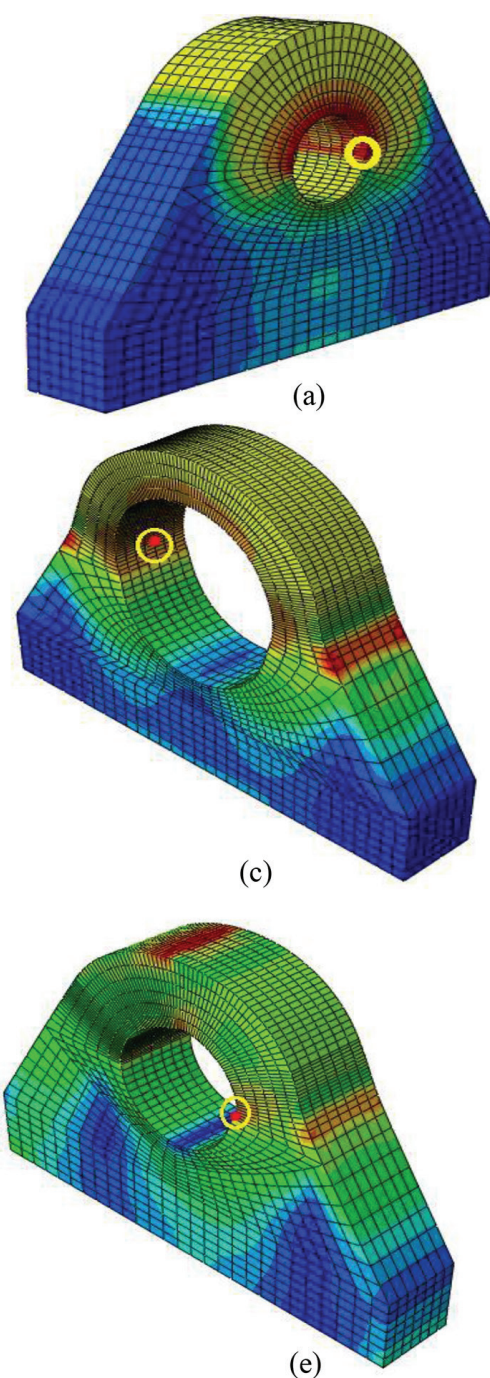
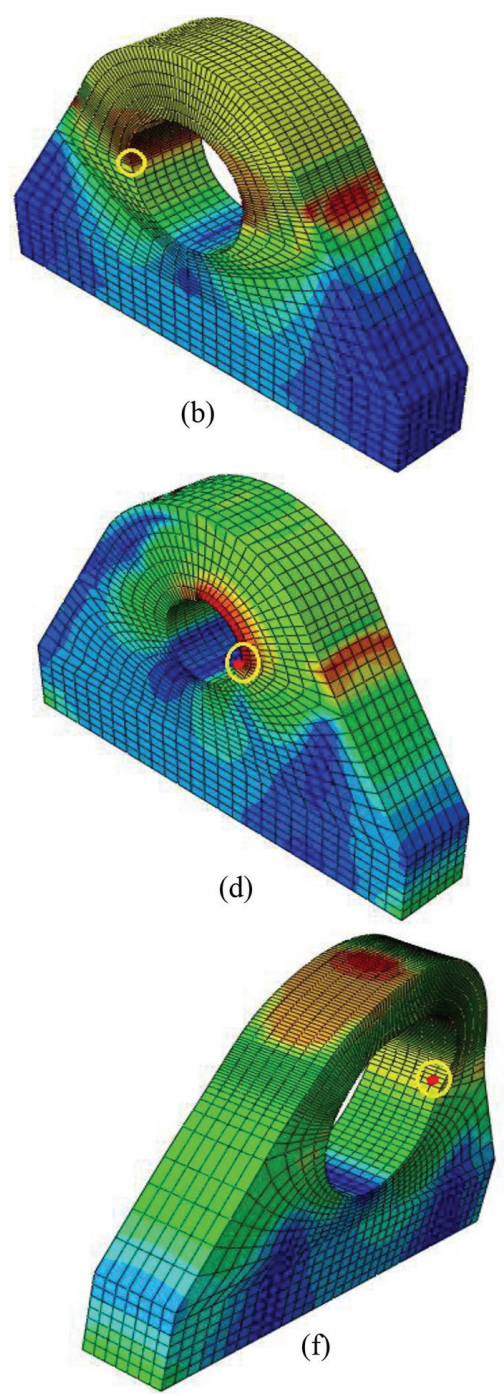

Figure 8: Stress distribution and fracture locations for case 1 (i.e. pad eyes with out base plate): (a) Test 1, (b) Test 3, (c) Test 4, (d) Test 5, (e) Test 6, (f) Test 7.

theoretical design load, without going to failure, and can withstand larger loads than their experimental counterparts. This shows that, when following the standards (as the pad eye geometries, on which test 1 is based, are in accordance with NORSOK R-002 [1], while tests two and three are not totally based on NORSOK R-002), very reliable and precise simulation results can be obtained. Moreover, it can be seen from the table that the amount of displacement for the pad eye with the plate is much greater and closer to the experimental results than for the pad eye without the plate; this is due to the fact that this deformation of the plate is now also a part of the global deformation of the pad eye. From Table 1, it can be seen that the experimental load capacity has no particular value, as it is $>21$ tons, which means that it can carry more than 21 tons without being subjected to failure. 


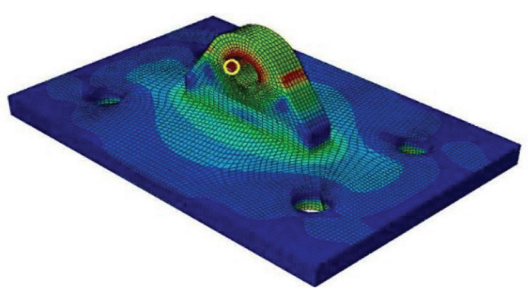

(a)

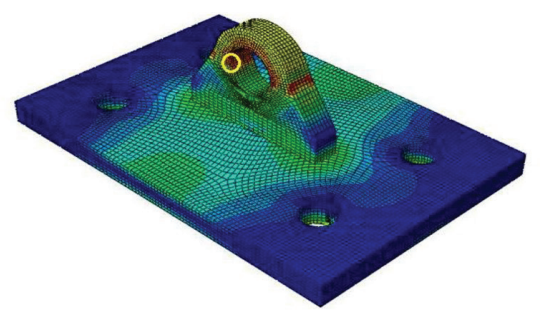

(b)

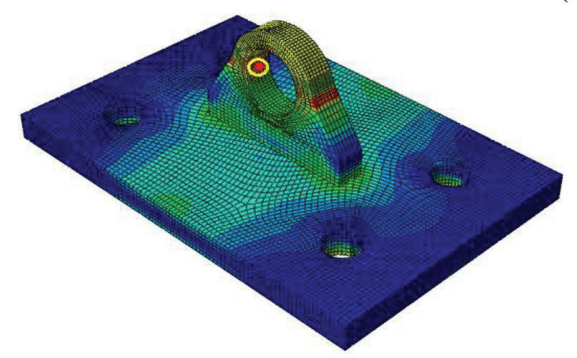

(c)

Figure 9: Stress distribution and fracture locations for case 1 (i.e. pad eyes with base plate):

(a) Test 1, (b) Test 3, (c) Test 4.

Test 3: In the case where the pad eye is without the plate, the load capacity given by FE analysis is larger than both the theoretical and the experimental load capacities, while the displacements are again far from the experimental results. In the case of the pad eye with the plate, the simulation load capacity is even larger. Regarding the displacements, it is again observed that the displacement for the pad eye with the plate is much greater than that for the pad eye without the plate, and it is also closer to the experimental result.

Test 4: In the case where the pad eye is without the plate, the load capacity given by FE analysis is much larger than both the theoretical and the experimental load capacities. In the case of the pad eye with the plate, the simulation load capacity is even greater. Regarding the displacements, it is not possible to compare the results at this stage, since the deformation has no particular value: only 'large deformation' is noted.

Test 5: This test only contains the pad eye without plate; the load capacity given by FE analysis is smaller than the theoretical and larger than the experimental load capacity. It is also noticeable that the load capacity in Test 5 (22.493 tons), which is an angled loading, is smaller than the load capacity in Test 1 (25.575 tons), which is a vertical loading.

Test 6: This test only contains the pad eye without plate; the load capacity given by FE analysis is close to the theoretical and much larger than the experimental load capacity.

Test 7: In this test, which only contains the pad eye without plate, the load capacity given by $\mathrm{FE}$ analysis is much larger than both the theoretical and the experimental load capacities.

\section{CONCLUSIONS}

The comparison results showed positive signs to some extent, as some of the results predicted by FE analysis were very close to the theoretical and the experimental results, while 
others were quite far from them. There are several factors that could be behind this deviation:

- In reality, the actual material can withstand greater loads than the characteristic values used in the design standards. The effect of safety factors, which lead to safer designs, may significantly influence these deviations.

- Uncertainty in material behavior may have caused these deviations.

Although there was some discrepancy between the numerical results obtained from the different approaches, the result patterns were the same. It has been realized that the capacity of the pad eyes reduces when the pinhole diameter size increases, which demonstrates the importance of following the standard requirements. Furthermore, the results show that the pad eyes with the base plate have greater capacity than the pad eyes without the plates. Finally, a reduction in the load capacity is recognized in the angled loading case, when compared to the vertical loading case, even though the theoretical capacities provide the same results for both cases. Probabilistic FE simulation is recommended for future studies in order to obtain a more precise comparison, while considering the uncertainties of both material behavior and loadings.

\section{REFERENCES}

[1] NORSOK R-002, NORSOK standard. Lifting equipment, 2012.

[2] NORSOK N-001, Integrity of offshore structures, rev. 8, September 2012.

[3] Haver, S., Weather windows for marine operations, Statoil, Norway, 1999.

[4] NORSOK R-003, NORSOK standard. Safe use of lifting equipment, 2004.

[5] Adasooriya, N.D., Siriwardane, S.C. \& Ohga, M., A simplified approach to predict the failure of steel members under interaction effect of fracture and fatigue. International Journal of Fatigue, 47, pp. 161-173, 2013. https://doi.org/10.1016/j.ijfatigue.2012.08.007

[6] Kanvinde, A.M. \& Deierlein, G.G., Void growth model and stress modified critical strain model to predict ductile fracture in structural steels. Journal of Structural Engineering, 132, pp. 1907-1918, 2006. https://doi.org/10.1061/(asce)0733-9445(2006)132:12(1907)

[7] Kvalvåg, R., Offshore hook-up project management, Master's Thesis, University of Stavanger, Norway, 2014.

[8] NORSOK N-004, NORSOK standard. Design of steel structures, 2004. 